\title{
PENGARUH MODEL PEMBELAJARAN INKUIRI TERBIMBING BERBANTUKAN BUKU SISWA BERBASIS PENDEKATAN TERPADU STEM TERHADAP HASIL BELAJAR
}

\author{
Salma Faizah Amatullah \\ I Wayan Distrik \\ Ismu Wahyudi \\ Pendidikan Fisika, FKIP, Universitas Lampung \\ Email: faizah.salma17@gmail.com
}

\begin{abstract}
Abstrak
Pembelajaran monoton dapat mematikan daya berpikir kreatif siswa, karena siswa mengalami kebosanan dalam proses pembelajaran. Penelitian ini bertujuan untuk mengetahui pengaruh model pembelajaran inkuiri terbimbing berbantukan buku siswa berbasis pendekatan terpadu STEM terhadap hasil belajar siswa dan mendeskripsikan hasil belajar siswa setelah menggunakan model pembelajaran inkuiri terbimbing berbantukan buku siswa berbasis pendekatan terpadu STEM. Populasi pada penelitian ini seluruh siswa kelas XSMAIT Miftahul Jannah, dan sampel yang dipilih dengan teknik purposive sampling siswa kelas X1sebagai kelas eksperimen dan siswa kelas X2 sebagai kelas kontrol. Penelitian ini menggunakan pretest posttest control group design terhadap dua kelas yaitu kelas eksperimen dan kelas kontrol. Pada penelitian ini, kedua kelas dibandingkan sesuai dengan hasil belajarnya lalu dilakukan uji perbedaan kedua kelompok siswa menggunakan Independent Sample T-test. Berdasarkan hasil penelitian menunjukkan perbedaan hasil belajar pada siswa dikelas eksperimen dan kelas kontrol dengan ratarata $\mathrm{N}$ gain berturut-turut, yaitu 0,62 dan 0,30 dan hasil uji independent sample $t$ test $t_{\text {hitung }}>t_{\text {tabel }}$ yaitu 5,485 $>2,069$ pada taraf kepercayaan $95 \%$, ini menunjukkan bahwa terdapat pengaruh signifikan terhadap pengaruh model pembelajaran inkuiri terbimbing berbantukan buku siswa berbasis pendekatan terpadu STEM terhadap hasil belajar.
\end{abstract}

Kata Kunci: Buku Siswa, Hasil Belajar, Inkuiri Terbimbing, STEM.

\section{PENDAHULUAN}

Undang-Undang No 20 Tahun

2003 pasal 3 Pemerintah telah mengatur sistem pendidikan yang menyebutkan bahwa pendidikan nasional berfungsi mengembangkan kemampuan dan membentuk watak serta peradaban bangsa yang 
bermartabat dalam rangka pelajaran 2017/2018 adalah 28,54 mencerdaskan bangsa dan bertujuan dengan nilai KKM, yaitu 73,00. Hal untuk mengembangkan potensi ini menjadikan banyak siswa harus peserta didik. Sistem pendidikan lebih menekankan pada pembelajaran yang mengembangkan potensi peserta didik agar menjadi manusia yang beriman dan bertakwa kepada Tuhan Yang Maha Esa, berakhlak mulia, sehat, berilmu, cakap, kreatif, mandiri, dan menjadi warga negara yang demokratis serta bertanggung jawab sesuai dengan cita-cita Pendidikan ideal yang telah diatur oleh Pemerintah di Undang-Undang No 20 Tahun 2003 pasal 3.

Pembelajaran yang monoton dirasa akan semakin merendahkan daya berpikir kreatif siswa, karena siswa mengalami kebosanan dalam proses pembelajaran. Rendahnya daya berpikir kreatif siswa berdampak pada rendahnya hasil belajar siswa khususnya mata pelajaran fisika. Hasil belajar siswa untuk mata pelajaran fisika relatif masih di bawah Kriteria Ketuntasan Minimal (KKM), seperti halnya yang terjadi di SMA IT Miftahul Jannah. Peneliti memperoleh data nilai rata-rata fisika siswa pada Ujian Semester I kelas $\mathrm{X}$ tahun melakukan program remedial untuk meningkatkan nilainya menjadi di atas nilai KKM.

Berdasarkan hasil wawancara dengan guru fisika, belum tercapainya hasil belajar fisika siswa yang memuaskan di SMA IT Miftahul Jannah disebabkan karena hal-hal berikut: 1) siswa kurang diikutsertakan dalam partisipasi proses belajar mengajar; 2) bahan ajar yang digunakan kurang bervariasi dan tidak menarik perhatian siswa, contohnya buku ajar; 3) kurang dioptimalkannya penggunaan media pembelajaran sesuai dengan karakteristik materi fisika, sehingga materi yang disampaikan tidak dapat dipahami siswa dengan baik; 4) aktivitas siswa seperti menge-mukakan pendapat, menjawab pertanyaan dan mendebat pernyataan masih belum muncul selama proses pembelajaran; 5) guru belum sepenuhnya memperhatikan ke-mampuan verbal siswa sehingga metode yang digunakan kadang tidak sesuai dengan kebutuhan siswa. 
Menurut Attard et al., (2010) dan tim dari Education International dan European Students' Union proses belajar terbaik adalah dengan melibatkan para siswa untuk mempelajari materi pelajaran secara aktif. Di saat yang sama, guru juga lebih berperan dalam memfasilitasi para siswanya belajar. Beberapa fasilitasi tersebut seperti menugaskan melaksanakan eksperimen, memberi mereka peluang untuk memnyajikan hasil kajian, berdiskusi dengan peer group, dan belajar menyimpulkan hasil diskusinya. Angele Attard membuat perbandingan capaian hasil belajar yaitu belajar dengan model passive learning melalui ceramah, membaca, audio-visual, dan demonstrasi hanya mampu menghasilkan pencapaian belajar paling tinggi 30\%. Bahkan bila hanya mengandalkan audio-visual, membaca, pencapaian materi pelajaran yang bisa melekat dan diingat masing-masing hanya mencapai 20\%, $10 \%$ dan bahkan 5\%. Persentase pencapaian demikian jauh berbeda dengan model belajar aktif melalui diskusi, praktik, atau mengajar orang lain. Pencapaian dicatatkan 50\% pada metode diskusi. Sedangkan praktek dan mengajar yang lain mencatatkan prosentase hasil belajar lebih tinggi, yakni $75 \%$ dan $90 \%$. Pengajaran metode terakhir dilakukan dengan menjelaskan informasi pengetahuan yang dipelajarinya pada peer groupnya dengan saling bertanya, berdialog, berdiskusi atau bahkan berdebat. Pengajaran dengan metode tersebut disebut dengan pengajaran secara SCL atau Student Centre Learning yang saat ini sangat direkomendasikan agar siswa mampu meraih hasil belajar yang maksimal.

SCL ini dapat menggunakan Pendekatan STEM. STEM terdapat empat aspek diantaranya sains, teknologi, teknik atau engineering, dan matematika (Force, 2014: 7). STEM adalah sebuah pembelajaran yang membantu siswa untuk (a) meningkatkan pengetahuan ilmiah dan statistik, prinsip dan proses (b) mengasah kemampuan penelitian ilmiah mereka dan (c)memperdulikan lingkungan sosial. Pendidikan STEM melibatkan integrasi dengan dunia nyata, dan siswa sering membuat contoh dari dunia nyata (McCright, 2012). 
Pembelajaran dengan meng- pemberi bimbingan jika diperlukan gunakan pendekatan STEM bertujuan oleh siswa. Salah satu model agar siswa memiliki hard skilsyang diimbangi dengan soft skills, karena dalam proses pembelajarannya dilakukan dengan metode active learning yang meliputi komunikasi, kolaborasi, problem solving, dan kreativitas, serta dapat mendorong siswa untuk belajar tentang alam melalui eksplorasi, penyelidikan, dan pemecahan masalah sesuai pengalamanya (Asghar et al, 2012).

Inkuiri merupakan kegiatan belajar yang melibatkan secara maksimal seluruh kemampuan siswa untuk mencari dan menyelidiki secara sistematis, kritis, logis, analitis (Gulo, 2004: 84). Melalui pembelajaran dengan menggunakan model pembelajaran inkuiri, siswa belajar sains sekaligus juga belajar model sains. Proses inkuiri memberikan kesempatan kepada siswa untuk memiliki pengalaman belajar yang nyata dan aktif, siswa dilatih bagaimana memecahkan masalah sekaligus membuat keputusan. Peran guru di dalam proses pembelajaran dengan menggunakan model pembelajaran inkuiri lebih sebagai pembelajaran inkuiri adalah model pembelajaran inkuiri terbimbing. Model pembelajaran inkuiri terbimbing merupakan pembelajaran yang terpusat pada siswa atau pembelajaran secara SCL. Menurut Dewi et al., (2013) model pembelajaran inkuiri terbimbing yang melibatkan siswa secara aktif mempunyai kelebihan bagi siswa yang ditekankan dalam mempresentasikan hasil eksperimen mereka, sehingga siswa akan secara aktif terlibat dalam pembelajaran. Dengan demikian, pembelajaran menggunakan model pembelajaran inkuiri terbimbing yang merupakan pembelajaran yang terpusat pada siswa atau SCL yang kegiatan pembelajaranya menekankan active learning pada proses berpikir kritis, sistematis, logis, dan analitis (Gulo 2004: 84) dan menggunakan pendekatan terpadu STEM yang mendorong siswa untuk belajar melalui eksplorasi, penyelidikan, dan pemecahan masalah sesuai pengalamanya ( Asghar et al., 2012) hal ini sangat direkomendasikan agar 
siswa mampu meningkatkan hasil belajar yang maksimal.

Buku siswa merupakan salah satu contoh dari sumber belajar yang penting saat diadakannya pembelajaran. Menurut Kuhlthau et al., (2007: 61) sumber belajar yang berkualitas tinggi merupakan stimulus bagi pembelajaran inkuiri. Perpaduan buku ajar berbasis STEM yang melibatkan integrasi mata pelajaran dengan yang sering dihadapi siswa sepanjang hari, dan mengintegrasikannya dengan dunia nyata, serta model pembelajaran inkuiri terbimbing yang digunakan secara maksimal oleh siswa untuk mencari dan menyelidiki secara sistematis, kritis, logis, analitis dapat membantu guru dan siswa dalam meningkatkan hasil belajar siswa.

Perpaduan buku ajar berbasis STEM yang melibatkan integrasi mata pelajaran dengan yang sering dihadapi siswa sepanjang hari, dan mengintegrasikannya dengan dunia nyata, serta model pembelajaran inkuiri terbimbing yang digunakan secaramaksimal oleh siswa untuk mencari dan menyelidiki secara sistematis, kritis, logis, analitis dapat membantu guru dan siswa dalam meningkatkan hasil belajar siswa.

Berdasarkan yang telah dipaparkan, maka dilakukanlah penelitian yang berjudul, "Pengaruh Model Pembelajaran Inkuiri Terbimbing Berbantukan Buku Siswa Berbasis Pendekatan Terpadu STEM terhadap Hasil Belajar" dengan tujuan penelitian ini adalah untuk mengetahui pengaruh model pembelajaran inkuiri terbimbing berbantukan buku siswa berbasis pendekatan terpadu STEM terhadap hasil belajar siswa dan mendeskripsikan hasil belajar siswa setelah menggunakan model pembelajaran inkuiri terbimbing berbantukan buku siswa berbasis pendekatan terpadu STEM.

\section{METODE}

Populasi penelitian ini, yaitu seluruh siswa kelas $\mathrm{X}$ (sepuluh) SMA IT Miftahul Jannah pada semester genap tahun pelajaran 2017/2018. Teknik pengambilan sampel pada penelitian ini menggunakan teknik purposive sampling, yaitu dengan dipilihnya dua kelas. Dengan rincian kelas yang 
menjadi sampel adalah satu kelas sebagai kelas eksperimen dan satu kelas yang lain sebagai kelas kontrol.

Penelitian ini menggunakan Pretest Posstest Control Group Design. Kedua kelas tersebut terdiri dari kelas eksperimen dan kelas kontrol. Kedua kelas diberikan pretest dan posttest, yang kemudian hasil $\mathrm{N}$-gain nya dibandingkan. Secara umum desain penelitian ditunjukkan pada Tabel 1.

Tabel 1. Desain Penelitian

\begin{tabular}{cccc}
\hline Kelas & Pretest & Perlakuan & Postest \\
\hline Eksperimen & $\mathrm{O}_{1}$ & $\mathrm{X}_{1}$ & $\mathrm{O}_{2}$ \\
Kontrol & $\mathrm{O}_{3}$ & $\mathrm{X}_{2}$ & $\mathrm{O}_{4}$ \\
\hline
\end{tabular}

\begin{abstract}
Kelas eksperimen adalah kelas yang mendapatkan perlakuan menggunakan model pembelajaran inkuiri terbimbing dan didukung oleh buku siswa yang berbasiskan
\end{abstract} STEM sedangkan kelas kontrol menggunakan model pembelajaran ceramah dan didukung buku siswa berbasiskan konvensional. Penilaian hasil belajar siswa pada ranah kognitif dilakukan dengan menggunakan soal pilihan jamak yang sama pada pretest dan posttest.

Penelitian ini terdiri dari dua variabel penelitian yaitu variabel bebas dan variabel terikat dan terdapat satu moderator. Variabel bebas dalam penelitian ini adalah model pembelajaran inkuiri terbimbing, variabel terikatnya adalah hasil belajar siswa dan dimoderatori oleh buku siswa berbasis pendekatan terpadu STEM.

Sebelum instrumen kognitif digunakan dalam sampel, instrumen diuji terlebih dahulu dengan uji validitas dan uji reliabilitas dengan menggunakan program SPSS versi 21.0. Data yang diperoleh setelah melakukan pretest dan posttest dalam penelitian ini terdiri atas instrumen kognitif dengan jumlah 12 berbentuk soal pilihan jamak. selanjutnya dianalisis dengan uji Ngain, uji normalitas, uji homogenitas, dan uji Independent Sample T-test. 
Data hasil belajar siswa dianalisis menggunakan skor gain yang ternormalisasi. Uji normalitas dilakukan terhadap data pretest dan posttest hasil belajar siswa ranah kognitif yang telah didapat dari hasil pembelajaran pada kelas eksperimen dan kontrol.

Uji normalitas pada penelitian ini menggunakan uji kolmogorov smirnov. Data dikatakan berdistribusi normal jika pada Kolmogorov Smirnov nilai Sig.> 0.05 , sebaliknya data dengan nilai Sig. $<0.05$ tidak berdistribusi normal (Arikunto, 2012: 111). Selanjutnya adalah uji homogenitas. Kemudian, dilakukan uji Independent Sample Ttest untuk membandingkan dua sampel bebas serta mengetahui ada tidaknya peningkatan rata-rata dua kelompok sampel yang tidak berhubungan.

Berdasarkan hasil uji Independent Sample T-test dapat diketahui diterima atau tidaknya hipotesis yang telah dibuat. Kriteria pengujiannya adalah jika probabilitas (Asymp.Sig) < 0.05, maka $\mathrm{H}_{0}$ ditolak, jika probabilitas (Asymp. Sig) >0.05, maka $\mathrm{H}_{0}$ diterima.

\section{HASIL DAN PEMBAHASAN}

Hasil Uji Validitas dan Reliabelitas

Hasil uji Validitas terdapat $\mathrm{N}=19$ dan $\alpha=0,05$ maka $r_{\text {tabel }}=0,433$ dan dan dari 20 soal yang diuji terdapat 12 butir soal memiliki Pearson Correlation $>0,433$ sehingga 12 butir soal tersebut valid dan 8 butir soal yang lainnya atau yang tidak valid dibuang.

Soal yang telah diuji kevalidannya, selanjutnya soal diuji reabilitasnya, hasil uji reabilitas nilai Cronbach's Alpha sebesar 0,769, sehingga 12 butir soal kognitif bersifat reliabel dan tergolong tinggi, karena nilai Cronbach's Alpha berada diantara 0,600 sampai dengan 0,800.

Berdasarkan Tabel 2. dapat diketahui bahwa data $\mathrm{N}$-gain pada kelas eksperimen dan kelas kontrol memiliki distribusi normal, dimana nilai Asymp. Sig (2-tailed) lebih dari 0,050 yaitu 0,73 pada kelas eksperimen dan 0,12 pada kelas kontrol. Hasil ini merupakan salah satu syarat terpenuhinya untuk melakukan uji dua sampel bebas dengan menggunakan Independent Sample T-test. 
Tabel 2. Hasil Uji Normalitas N-gain Kognitif

\begin{tabular}{ccccc}
\hline Parameter & \multicolumn{2}{c}{ Kelas Eksperimen } & \multicolumn{2}{c}{ Kelas Kontrol } \\
& Pretest & Posttest & Pretest & Posttest \\
\hline Jumlah Siswa & 14 & 14 & 11 & 11 \\
Rata-rata & 29,55 & 73,48 & 24,40 & 48,21 \\
Nilai Tertinggi & 66,67 & 91,67 & 50,00 & 75,00 \\
Nilai Terendah & 00,00 & 66,67 & 00,00 & 33,33 \\
\hline N-gain & \multicolumn{2}{c}{0,62} & \multicolumn{2}{c}{0,3} \\
Asymp. Sig (2-tailed) & \multicolumn{2}{c}{0,73} & \multicolumn{2}{c}{0,12} \\
\hline
\end{tabular}

Selanjutnya dilakukan pengujian dua sampel bebas menggunakan Independent Sample T-test untuk mengetahui ada tidaknya perbedaan hasil belajar ranah kognitif sebelum dan sesudah dilakukan pembelajaran pada masing-masing kelas (eksperimen dan kelas kontrol). Adapun yang diuji adalah perbedaan rata-rata $\mathrm{N}$-gain dari masing-masing kelas eksperimen dan kontrol. Hasil Uji Independent Sample T-test pada ranah kognitif ditampilkan pada Tabel 3.

Tabel 3. Hasil Uji IndependentSample T-test pada ranah kognitif

\begin{tabular}{|c|c|c|c|c|c|c|c|c|c|c|}
\hline & & \multicolumn{2}{|c|}{$\begin{array}{c}\text { Levene's } \\
\text { Test for } \\
\text { Equality of } \\
\text { Variances } \\
\end{array}$} & \multicolumn{7}{|c|}{ t-test for Equality of Means } \\
\hline & & \multirow[t]{2}{*}{$\mathbf{F}$} & \multirow[t]{2}{*}{ Sig. } & \multirow[t]{2}{*}{$\mathbf{t}$} & \multirow[t]{2}{*}{ Df } & \multirow[t]{2}{*}{ Sig. } & \multirow{2}{*}{$\begin{array}{c}\text { Mean } \\
\text { Differen } \\
\text { ce }\end{array}$} & \multirow[t]{2}{*}{$\begin{array}{l}\text { Std. Error } \\
\text { Difference }\end{array}$} & \multicolumn{2}{|c|}{$\begin{array}{l}\text { 95\% Confidence } \\
\text { Interval of the } \\
\text { Difference }\end{array}$} \\
\hline & & & & & & & & & Lower & Upper \\
\hline$N$ gain & $\begin{array}{c}\text { Equal } \\
\text { variances } \\
\text { assumed }\end{array}$ & $\begin{array}{c}1.31 \\
8\end{array}$ & .263 & 5.485 & 23 & .000 & .32013 & .05837 & .19938 & .44088 \\
\hline
\end{tabular}

Berdasarkan Tabel 3, nilai $t_{\text {hitung }}$ Equal Varians Assumed pada tabel sebesar 5,485 sedangkan $t_{\text {abel }}$ sebesar 2,069. Nilai $t_{\text {hitung }}>t_{\text {tabel }}(5,485>$ 2,069) dan signifikansi $(0,000<0,05)$ maka $\mathrm{H}_{0}$ ditolak. Tabel 3. membuktikan bahwa menurut uji Independent Sample T-test terdapat perbedaan hasil belajar siswa ranah kognitif kelas eksperimen dan kelas kontrol secara siginifikan. Maka, dapat disimpulkan bahwa terdapat 
pengaruh penggunaan model langsung atau metode ceramah pembelajaran inkuiri terbimbing berbantukan buku konvensional berbantukan buku siswa berbasis siswa, rata-rata hasil belajar ranah STEM terhadap hasil belajar siswa kognitif meningkat menjadi 48,21. pada ranah kognitif materi suhu dan kalor.

\section{Pembahasan}

Rata-rata hasil belajar siswa pada kelas eksperimen ranah kognitif sebelum diterapkan pembelajaran dengan menggunakan model pembelajaran inkuiri terbimbing berbantukan buku siswa berbasis STEM hanya sebesar 29,55. Setelah diterapkan pembelajaran dengan menggunakan model pembelajaran inkuiri terbimbing berbantukan buku siswa berbasis STEM, hasil belajar siswa ranah kognitif meningkat menjadi 73,48 . Terjadi peningkatan rata-rata hasil belajar siswa ranah kognitif sebesar 43,93. Sementara itu, rata-rata hasil belajar siswa ranah kognitif pada kelas kontrol sebelum diterapkan pembelajaran dengan menggunakan model pembelajaran langsung atau metode ceramah berbantukan buku konvensional siswa hanya sebesar 24,40. Setelah diterapkan pembelajaran menggunakan model pembelajaran Terjadi peningkatan rata-rata hasil belajar siswa ranah kognitif sebesar 23,81. Jika dilihat berdasarkan nilai KKM yakni 73,0, rata-rata hasil belajar siswa ranah kognitif kelas eksperimen memiliki nilai di atas KKM yaitu 73,48, sedangkan kelas kontrol memiliki rata-rata di bawah KKM yaitu 48,21.

Perbedaan nilai rata-rata hasil belajar siswa ranah kognitif pada kelas eksperimen dan kelas kontrol dapat dilihat dari model pembelajaran yang digunakan guru dalam proses pembelajaran. Menurut Dewi et al., (2013) model pembelejaran inkuiri terbimbing yang melibatkan siswa secara aktif mempunyai kelebihan bagi siswa dalam mempresentasikan hasil eksperimen mereka, sehingga siswa akan secara aktif terlibat dalam pembelajaran dan menurut Attard et al., (2010) dan tim dari Education International dan European Students Union proses belajar terbaik adalah dengan melibatkan para siswa untuk mempelajari materi pelajaran secara 
aktif. Di saat yang sama, guru juga lebih berperan dalam memfasilitasi para siswanya belajar. Beberapa fasilitasi tersebut seperti menugaskan melaksanakan eksperimen, memberi mereka peluang untuk mempresentasikan hasil kajian, berdiskusi dengan peer group, dan belajar menyimpulkan hasil diskusinya. Model passive learning melalui ceramah, membaca, audiovisual, dan demonstrasi yang dilakukan di kelas kontrol hanya mampu menghasilkan pencapaian belajar 5\% - 30\% yaitu 23,81 \% Prosentase pencapaian demikian jauh berbeda dengan model belajar aktif melalui diskusi, praktik, atau mengajar orang lain, seperti yang dilakukan di kelas eksperimen. Pencapaian belajar dapat mencapai $31 \%-50 \%$, yaitu 48,21\%.

Pembelajaran pada eksperimen dapat berkolaborasi dengan guru merupakan langkah menuju integrasi disiplin ilmu, mencerminkan dengan lebih baik apa yang sesungguhnya terjadi di luar kelas.. Hal ini relevan dengan pendapat mengenai definisi STEM dari (Chiu, Price, Ovrahim, \& Ed, 2015) dan California Departement of Education dalam Force (2014: 43), bahwa STEM dapat menjadikan siswa aktif, kolaboratif, terampil, dan pembelajaran dapat bermakna dan mengintegrasikan dengan dunia nyata sehingga memperluas pengetahuan.

Pembelajaran berbantukan buku siswa berbasis STEM telah diuji berdasarkan kemenarikan, kemudahan dan kebermanfaatan diperoleh skor sebesar 3,50 yang berarti produk hasil pengembangan buku siswa berada dalam kualitas sangat baik. Buku berbasis STEM ini dapat menjadikan siswa aktif, kolaboratif, terampil, dan pembelajaran dapat bermakna dan mengintegrasikan dengan dunia nyata sehingga memperluas pengetahuan. Sesuai dengan peningkatan hasil belajar siswa yang mencapai 48,21\%. Bahwa buku siswa tersebut dapat meningkatkan hasil belajar siswa, membantu siswa untuk mendapatkan penguasaan kompetensi yang dibutuhkan untuk mengerjakan tugas, menolong siswa untuk dapat mengembangkan disiplin intelektual dan keterampilan berpikir dengan memberikan pertanyaan dan mendapatkan jawaban atas dasar keingintahuan siswa. Menurut W. 
Guyotte (2015) pendekatan STEM berbantukan buku konvensional yang yang melibatkan siswa dalam mempunyai pengaruh lebih rendah. eksplorasi interdisipliner per- Perbandingan antara rata-rata N-gain masalahan yang kompleks dapat hasil belajar siswa ranah kognitif menawarkan ruang dimana keduanya adalah 0,62:0,30. N-gain keterlibatan kolaboratif dengan hasil belajar siswa ranah kognitif memelihara prespektif yang lebih diperoleh dari data hasil penggunaan holistik, otentik, dan dialogis terhadap instrumen tes berupa pretest dan masalah-masalah yang ada. posttest. Rata-rata hasil belajar siswa Pendekatan ini mampu menciptakan sebuah sistem pembelajaran secara kohesif dan pembelajaran aktif karena keempat aspek dibutuhkan secara bersamaan untuk menyelesaikan masalah. Solusi yang diberikan menunjukkan bahwa peserta didik mampu untuk menyatukan konsep abstrak dari setiap aspek. Dengan demikian buku siswa berbasiskan STEM pada pokok bahasan suhu dan kalor dapat mengakomodasi hasil belajar yang baik.

Pembelajaran menggunakan model pembelajaran inkuiri terbimbing berbantukan buku siswa berbasis STEM mempunyai pengaruh yang cukup tinggi karena rata-rata $\mathrm{N}$-gain hasil belajar siswa pada ranah kognitif lebih tinggi dibandingkan menggunakan model pembelajaran langsung atau metode ceramah ranah kognitif diambil sebelum dan setelah diterapkannya pembelajaran menggunakan model pembelajaran inkuiri terbimbing berbantukan buku siswa berbasis STEM dan pembelajaran menggunakan model pembelajaran langsung atau metode ceramah berbantukan buku konvensional siswa. Hal ini digunakan untuk mengetahui peningkatan hasil belajar siswa baik ranah kognitif.

Berdasarkan hasil uji Independent Sample T-test perbedaan signifikan pada $\mathrm{N}$-gain antara kelas eksperimen dan kelas kontrol thitung $>$ ttabel yaitu 5,485 > 2,069 pada taraf kepercayaan 95\%, hal ini dapat disimpulkan bahwa terdapat pengaruh penggunaan model pembelajaran inkuiri terbimbing berbantukan buku siswa berbasis STEM terhadap hasil belajar siswa 
pada ranah kognitif materi suhu dan kalor. Hasil tersebut relevan dengan penelitian Erliana (2011) pada penelitiannya yang menyatakan bahwa $t_{\text {hitung }}>\mathrm{t}_{\text {tabel }}$ yaitu $2,94>1,98$. Dengan demikian $\mathrm{H}_{0}$ ditolak dan $\mathrm{H}_{1}$ diterima pada taraf kepercayaan 95\%, hal ini menunjukkan bahwa terdapat pengaruh yang signifikan antara ratarata skor posttest kelas eksperimen dengan rata-rata skor posttest kelas kontrol, dan dapat diartikan bahwa terdapat pengaruh model pembelajaran inkuiri terbimbing terhadap hasil belajar siswa.

Berdasarkan analisis data dan pendapat-pendapat yang mendukung, dapat dinyatakan bahwa belajar menggunakan model pembelajaran inkuiri terbimbing berbantukan buku siswa berbasis STEM lebih efektif dibandingkan dengan model pembelajaran langsung atau metode ceramah berbantukan buku konvensional.

\section{PENUTUP}

\section{Kesimpulan}

Berdasarkan data hasil penelitian dan pembahasan, dapat disimpulkan bahwa terdapat pengaruh signifikan pembelajaran dengan model inkuiri terbimbing berbantukan buku siswa berbasis pendekatan terpadu STEM, yang ditunjukkan berdasarkan perbedaan signifikan pada $\mathrm{N}$-gain antara kelas eksperimen dan kelas kontrol thitung > ttabel yaitu 5,485 > 2,069 pada taraf kepercayaan 95\%, hal ini menunjukkan bahwa terdapat pengaruh model pembelajaran inkuiri terbimbing terhadap hasil belajar dan terdapat perbedaan hasil belajar pada siswa dikelas eksperimen dan kelas kontrol. Adapun nilai rata-rata hasil belajar antara kelas eksperimen dan kelas kontrol berturut-turut, yaitu 73,48 dan 48,21 .

\section{Saran}

Berdasarkan simpulan dari hasil penelitian, maka peneliti mengemukakan beberapa saran bahwa hasil belajar siswa yang tidak memenuhi KKM karena siswa kurang aktif, kolaboratif, dan bahan ajar yang kurang efektif, dalam proses pembelajaran guru dapat menggunakan bahan ajar berupa buku berbasis pendekatan STEM sebagai alternatif bagi guru-guru di sekolah sebagai salah satu upaya untuk 
meningkatkan hasil belajar siswa dan guru dapat memanfaatkan teknologi seperti simulasi atau video dalam pembelajaran untuk menjelaskan suatu konsep melalui representasi submikroskopik yang relatif sulit jika hanya dijelaskan secara verbal, sehingga siswa dapat memahami konsep secara jelas

\section{DAFTAR PUSTAKA}

Arikunto, Suharsimi. 2012. Dasardasar Evaluasi Penidikan ( $2^{\text {nd }} \mathrm{ed}$ ). Jakarta: Bumi Aksara.

Asghar, Anila, Roni Ellington, Eric Rice, Francine Johnson, and Glenda M. Prime. 2012. Supporting STEM Education in Secondary Science Contexts. Interdisciplinary Journal of Problem-Based Learning 6(2). Retrieved from http://docs.lib.purdue.edu/ijpbl/vol 6/iss $2 / 4$.

Attard, Di Ioio, Geven, and Santa. 2010. Student Centered Learning Toolkit for students, staff and Higher Education Institution., Education International and the European Student Union, Brussel, Belgia.

Chiu, Ashley, C.Aaron Price, Elsie Ovrahim, and M. Ed. 2015. Supporting Elementary and Middle School STEM Education at the Whole-School Level: A Review of the Literature. Museum of Science and Industry Chicago 1-21. Retrieved from https://www.msichicago.org/filead min/assets/educators/science_leade
rship_initiative/SLI_Lit_Review.p df .

Dewi, Narni Lestari, N. Dantes, and I.Wayan Sadia. 2013. Pengaruh Model Pembelajaran Inkuiri Terbimbing Terhadap Sikap Ilmiah Dan Hasil Belajar IPA. PENDASI: Jurnal Pendidikan Dasar Indonesia 3(1). Retrieved from http://pasca.undiksha.ac.id/ejournal/index.php/jurnal_pendas/ar ticle/view/512.

Force, S. T. (2014). Innovate A Blueprint for STEM Education Science (CA Dept of Education), (May), 7.

Gulo, W. 2004. Metodologi Penelitian. Jakarta: Grasindo.

Kuhlthau, C.C., Maniotes, L.K., dan Caspari, A.K., 2007. Guided Inquiry :Learning in 21st Century School. Greenwood Publishing Group, USA.

McCright, Aaron M. 2012. Enhancing Students' Scientific and Quantitative Literacies through an Inquiry-Based Learning Project on Climate Change. Journal of the Scholarship of Teaching and Learning 12(4):86-101. Retrieved from

http://search.proquest.com/docvie w/1314328364?accountid=13042 .

Peraturan Menteri Pendidikan dan Kebudayaan. (2003). Pemendikbud nomor 20. Tahun 2003, tentang Sistem Pendidikan Nasional..

W. Guyotte, Kelly., W. Sochacka, Nicola., E. Costantino, Tracie., N. Kellam, Nadia., Walther, Joachim., 2015. Collaborative Creativity in STEAM: Narratives of Art Education Students' Experiences in Transdisciplinary Spaces. 16, (15). 